\title{
A IMPORTÂNCIA DO LÚDICO NAS SÉRIES INICIAIS: ESTUDO DE CASO
}

\section{ARTIGO ORIGINAL}

ARAÚJO, Nadjane Melo Albuquerque ${ }^{1}$

OLIVEIRA, Nadja Lucia Melo Albuquerque ${ }^{2}$

OLIVEIRA, Manoel Messias Albuquerque De ${ }^{3}$

ARAÚJO, Nadjane Melo Albuquerque. OLIVEIRA, Nadja Lucia Melo Albuquerque. OLIVEIRA, Manoel Messias Albuquerque De. A importância do lúdico nas séries iniciais: Estudo de caso. Revista Científica Multidisciplinar Núcleo do Conhecimento. Ano 05, Ed. 06, Vol. 01, pp. 191-213. Junho de 2020. ISSN: 2448-0959, Link de acesso: https://www.nucleodoconhecimento.com.br/educacao/estudo-de-caso

\section{RESUMO}

Introdução: O presente estudo nasceu da necessidade de criar estratégias de aprendizagem com intuito de melhorar o ambiente e os conteúdos de forma prazerosa

\footnotetext{
${ }^{1}$ Mestre em Ciências da Educação (Universidade Interamericana/PY); Pós-graduada Lato Sensu em Educação Inclusiva, pela Faculdade Integradas de Jaquarepaguá, Rio de Janeiro; graduada em Pedagogia (Universidade Vale do Acaraú Fortaleza/Ceará). ${ }^{2}$ Mestre em Ciências da Educação (Universidade Interamericana/PY); Pós-graduada em Osteopatia Clínica Internacional pela Faculdade Inspirar Curitiba/Paraná. Graduada em Fisioterapia pela Faculdade Estácio de Sá Aracaju/Sergipe. Graduada em Pedagogia (Universidade Vale do Acaraú Fortaleza/Ceará).

${ }^{3}$ Pós-graduação Lato Sensu em Psicopedagogia Institucional, na Faculdade de Administração e Negócios de Sergipe - FANESE. Licenciatura em Português/Francês, pela Faculdade de Formação de Professores de Penedo/Alagoas (FFPP).
} 
para que os alunos sintam desejos de retornar a escola. Objetivo: Possibilitar uma aprendizagem significativa e prazerosa estimulando as potencialidades da criança. Metodologia: Trata-se de um estudo do tipo pesquisa de campo, qualitativo, quantitativo, analítico, prospectivo e transversal. Com uma amostra de 27 alunos do ensino fundamental ( $3^{\circ}$ ano) com idade entre 8 e 10 anos. A pesquisa foi realizada na Escola Estadual Pedro Alves de Souza, povoado Lagoa da Volta, Porto da Folha Sergipe, no período de 9 meses (março a dezembro). Foram desenvolvidas atividades lúdicas (caça palavras, ábaco, vaivém) para o ensino de Matemática, Português e Ciências. Resultados: Foram realizadas 40 atividades na disciplina de matemática, 60 atividades na disciplina de português e 40 atividades na disciplina de ciências. $\mathrm{Na}$ disciplina de matemática das 40 atividades todos os alunos concluíram as tarefas. $\mathrm{Na}$ disciplina de Português das 60 atividades, 35 foram concluídas e 25 não conseguiram concluir. Na disciplina de ciências das 40 atividades, 38 foram concluídas e 2 não conseguiram concluir. Conclusão: Logo, o lúdico como ferramenta auxiliar na construção das práticas pedagógicas, possibilitará ao aluno uma assimilação melhor dos conteúdos sem o peso da obrigação do cumprimento das tarefas, através do lúdico a criança aprende com alegria e prazer.

Palavras-Chave: Brincadeira, brinquedo, lúdico, aprendizagem, prazer.

\section{INTRODUÇÃO}

Há registros históricos que o homem primitivo fazia uso de diversos utensílios para sua comunicação e sobrevivência. Quando rabiscavam imagens ou traços nas cavernas, estavam praticando a comunicação de forma lúdica. As brincadeiras, os jogos e as danças são simétricos ao prazer e à aprendizagem. Segundo Huizinga (1971, p.07): "Nas sociedades primitivas as atividades que buscavam satisfazer as necessidades vitais, as atividades de sobrevivência como a caça, assumiam muitas vezes a forma lúdica".

$\mathrm{Na}$ atual conjectura, os alunos vivem em um mundo globalizado de diferentes circunstâncias sociais. Mesmos separados por séculos, o lúdico ainda preserva a 
magia de encantar e de dar prazer às tarefas mais árduas como o ensinar e aprender, da mesma forma como encantava o neandertal (HUIZINGA, 1971, p.07).

Comenta Fortuna (2011, p.11) que: além da interação, o lúdico e as brincadeiras aumentam a criatividade $\mathrm{e}$ as habilidades dos alunos, contribuindo para o desenvolvimento afetivo, psicológico, cognitivo e motor. Neste sentido, complementa Santos (1997, p.12) "A ludicidade é uma necessidade do ser humano em qualquer idade não apenas como diversão".

Nesse processo de evolução do ensino, é valoroso intensificar as brincadeiras e os jogos para fortalecer a atuação da cultura infantil, valorizando as experiências adquiridas que contribuem para formação da sua personalidade, tornando-o um ser capaz de reconstruir sua história. (KISHIMOTO, 1996).

É fato que a educação promove a integração do educando no universo social, comunitário e escolar, bem como a construção de uma visão própria do universo que o cerca. As atividades realizadas pelo educador possibilitarão ao mesmo o conhecimento das características do aprendiz, suas potencialidades e dificuldades, e Ihe subsidiarão no desenvolvimento de estratégias que promovam o desenvolvimento dessas potencialidades e a superação das dificuldades através da atividade lúdica (ILLICH, 1976).

Assim, esta pesquisa apresenta como relevante papel para a sociedade, pois, esperase provocar inquietações, mudanças de paradigmas, novos aprendizados e reconstrução do conhecimento, objetivando incluir um modelo favorável à aprendizagem, bem como, tornando-os críticos e ativos na sociedade da qual fazem parte. (DRUMONT, 2003).

Portanto, as brincadeiras em sala de aula não devem ser vistas como passa tempo, que por trás daquelas ações tão simples, esconde uma pedagogia voltada para aprendizagem e desenvolvimento cognitivo, psíquico e motor do aluno. 


\section{PROBLEMA DA INVESTIGAÇÃO}

De que maneira o lúdico facilita o processo de ensino aprendizagem na criança

\section{JUSTIFICATIVA}

O lúdico no ambiente escolar proporcionará aos discentes o desenvolvimento da oralidade e do pensamento, tornando-os capazes de buscar soluções para as dificuldades, como também, na relação interpessoal que propicia ao aluno entender o significado do respeito mútuo. Sendo assim, há uma perspectiva de melhora no rendimento escolar e consequentemente uma aprendizagem ampla e significativa.

\section{OBJETIVOS}

\section{OBJETIVO GERAL}

A importância do lúdico como parte integrante da prática pedagógica no processo de ensino aprendizagem.

\section{OBJETIVOS ESPECÍFICOS}

- Estimular a criança em seu desenvolvimento;

- Criar estratégias para facilitar a aprendizagem;

- Desenvolver o interesse da criança pelo conteúdo;

- Melhorar o índice da frequência escolar;

- Facilitar a interação entre alunos, professores e colegas;

- Possibilitar uma aprendizagem significativa e prazerosa.

\section{MARCO TEÓRICO}

\section{O LÚDICO NOS ANOS INICIAIS}

O lúdico como parte do processo de construção das práticas pedagógicas nas séries iniciais, representa uma proposta educacional para o desenvolvimento da criança e 
essencial para descobertas de novos saberes. Sendo assim, configura como uma importante ferramenta para nortear as ações e planejamento das atividades (DANTAS, 1998).

Para Vygotsky (1984), o brincar é importante para formação do pensamento infantil e que, através das brincadeiras e dos jogos a criança desenvolve habilidades cognitivas, visuais, auditivas, táteis e motora, as quais colaboram para uma relação interpessoal, fazendo descobertas e relacionando símbolos.

Vygotsky (1984, p.114), afirma que: "É a partir da brincadeira que a criança constrói o seu próprio pensamento". Para Kishimoto (1993), o brinquedo tem função lúdica e educativa, propicia diversão, prazer e até desprazer, e completa no individuo a compreensão de mundo. Vygotsky, (1984, p.114) acrescenta mais adiante: "a brincadeira cria para as crianças uma "zona de desenvolvimento proximal" que não é outra coisa senão a distância entre o nível atual de desenvolvimento, determinado pela capacidade de resolver independentemente um problema".

Atualmente, apesar dos múltiplos estímulos intelectuais que os brinquedos eletrônicos proporcionam às crianças, deve-se levar em consideração o déficit do desenvolvimento motor e das relações interpessoais, a criança começa a não mais interagir com o meio social, passa a ser sujeito da interação dos meios. De acordo com Dallabona e Mendes (2004, p.06): "É preciso quebrar alguns paradigmas e entender que o brinquedo é um investimento em crianças sadias do ponto de vista psicossocial".

\section{O LÚDICO NO PROCESSO DE DESENVOLVIMENTO COGNITIVO E MOTOR}

A ludicidade é fundamental para o desenvolvimento das habilidades motoras e cognitiva das crianças, as brincadeiras como: futebol, amarelinha, dominó, xadrez, pular corda, caça palavras, entre outros, estimulam o desenvolvimento global e propicia estilo de vida ativa e saudável. Kamii (2001, p.15), ressalta que: "o 
entretenimento desenvolve o raciocínio lógico matemático, através deles, as crianças são motivadas as contagens, à adição", entre outros conteúdos.

Vale ressaltar que a família constitui o primeiro contexto de educação e cuidado de um indivíduo. Nela a criança recebe cuidados materiais, afetivos e cognitivos necessários a seu bem-estar e assim construir suas primeiras formas de significar o mundo e as coisas. Quando a criança passa a frequentar a educação infantil é necessário refletir sobre a especificidade de cada contexto no desenvolvimento da criança. Conforme Gabriel Chalita, (2001, p.17) "Por melhor que seja uma escola, ela nunca vai suprir a carência de uma família ausente". Portanto, a família deve assumir o papel que the é outorgado no processo educativo.

\section{A BRINCADEIRA COLABORA NA APRENDIZAGEM}

O brincar causa na criança inúmeras sensações como representação, a imitação, do cotidiano ou de situações vividas anteriormente nas questões individuais e sociais, enfim, promove novas vivencias, o que suscita uma aprendizagem acompanhada pelo prazer. Para Cunha, (1994, p.67): "Brincando, a criança experimenta, descobre, inventa, exercita e confere suas habilidades".

Segundo Furth, (1974). A brincadeira torna a criança um ser brilhante, capaz de transmudá-la em um gigante na busca por resoluções de problemas. Para ele, a criança que brinca, vive uma infância feliz e transforma-se em um adulto muito mais equilibrado no físico e no emocional. Por conseguinte, essa criança na fase adulta conseguirá superar os problemas com mais facilidades.

Consoante Wallon (1979), o lúdico na educação infantil pode ser trabalhado em todas as atividades, portanto, é uma maneira de aprender e ensinar despertando o prazer, e dessa forma, a aprendizagem se realiza. Nessa nova construção do conhecimento a criança constrói novas habilidades.

Conforme autor acima citado, o lúdico viabiliza a construção do conhecimento de forma intrínseca e necessária para uma boa aprendizagem. Dessa maneira, a 
aprendizagem se estabelece na criança até a fase adulta e tal experiência converte em adultos maduros, autoconfiante e mais preparados para os desafios impostos pela sociedade.

O lúdico é um ingrediente indispensável no relacionamento entre pessoas, estimulando a criatividade. Os jogos e as brincadeiras, na sua existência, estão entrelaçados com as fases da vida do ser humano no desenvolvimento pessoal, social e cultural proporcionando uma boa saúde mental, facilita a comunicação, a expressão e a construção do conhecimento (PIAGET, 1976).

A brincadeira constitui para a criança um meio de socialização, oferecendo-Ihe oportunidades de realizar atividades coletivas, além de obter efeitos positivos na aprendizagem. Os estímulos cognitivos, afetivos e sociais são atribuídos através das brincadeiras. Para Wallon, (1979, p.81) "A criança aprende muito ao brincar".

O lúdico quando usado de maneira correta, oportuniza ao educador e educando, momentos de aprendizagem em múltiplos aspectos, favorecendo o desenvolvimento das potencialidades criativas. Ele deve ser encarado de forma séria, competente e responsável, pois, "a atividade lúdica é o berço das atividades intelectuais da criança" (PIAGET, 1976, p.160).

\section{O LÚDICO É IMPORTANTE EM QUALQUER IDADE}

O lúdico apresenta valores específicos para todas as fazes da vida humana, seja ela na idade infantil ou na adolescência, a finalidade é essencialmente pedagógica. De acordo com Neves (2009), a criança cria uma resistência à escola e ao ensino por não ser prazerosa já que não é apresentada de forma lúdica. É previsto pela constituição federal que toda criança tem direito a brincar e é dever das autoridades públicas e da sociedade assegurar esse direito. Antunes (2005, p.34), diz que: "Foi a partir do século $\mathrm{XVI}$, que os humanistas começaram a valorizar novamente o jogo educativo, percebendo a importância do processo lúdico na formação da criança". 
A educação lúdica representa uma ferramenta imprescindível para a educação. Segundo Santos, (2008, p.182). "A ludicidade é uma necessidade do ser humano em qualquer idade, onde facilita a aprendizagem e o desenvolvimento em qualquer aspecto, seja: cultural, pessoal, social ou mental". Na educação infantil, a criança constrói a aprendizagem por meio do brincar, criando ilusões entre o mundo real e suas fantasias.

A atividade lúdica prepara a criança para a vida, de modo que a insere na cultura do ambiente em que vive, aprende a competir, cooperar e trabalhar em equipe, transformando em um indivíduo social. Destarte, os professores não são meros transmissores de informações e conhecimentos sistemáticos, mas, mediadores desses conhecimentos. (FREIRE, 2001).

O conhecimento deve ser oportunizado através das atividades lúdicas, para que a criança desenvolva o conhecimento sobre si de forma autônoma. Visto que, as metodologias baseadas nas brincadeiras facilitam a aprendizagem e possibilita o fortalecimento do imaginário na construção do seu mundo. Segundo Friedmann (1996), O benefício é mútuo para o professor e para o aluno, por meio das trocas de aprendizado.

\section{MARCO METODOLÓGICO}

\section{TIPO DE ESTUDO}

Trata-se de um estudo do tipo pesquisa de campo, qualitativo, analítico, prospectivo e transversal. Inicialmente os responsáveis pelos alunos serão informados sobre a aplicação dos questionários da pesquisa e assinarão um Termo de Consentimento Livre e Esclarecido. Participaram da pesquisa alunos do $3^{\circ}$ ano do ensino fundamental.

Com o objetivo de validar a pesquisa foi aplicado três questionários, sob a supervisão da coordenadora do Colégio Estadual Pedro Alves de Souza, aos alunos, aos pais e 
à coordenadora para minimizar os possíveis vieses acerca da pesquisa. Foi explicado aos participantes em detalhes o objetivo do questionário.

\section{INSTRUMENTOS DE COLETA DE DADOS}

Os instrumentos utilizados para coleta de dados foram os questionários aplicados aos alunos, pais e coordenadora.

\section{POPULAÇÃO E AMOSTRA}

Escola da rede pública do Colégio Estadual Pedro Alves de Sousa, localizado na praça José Francisco de Sá S/N no povoado Lagoa da Volta no município de Porto da FolhaSe, no $3^{\circ}$ ano do ensino fundamental menor. A classe é composta por 27 alunos, sendo 15 meninos e 12 meninas, com idade entre 8 a 10 anos.

\section{ESTRATÉGIAS PARA CONSTRUÇÃO DAS ATIVIDADES}

\section{PORTUGUÊS}

Foram confeccionadas imagens que representavam as quatro formas das letras do alfabeto (cursivas, forma, maiúscula e minúscula), os alunos participaram de todo o processo de construção. Em seguida expuseram na parede para melhor identificar as letras quando houvesse dúvidas na construção das palavras.

\section{Jeito de brincar}

O jogo era parecido com "adedonha" a professora apontava para a letra que estava exposta na parede e os alunos falavam palavras que iniciasse com a letra apontada. Um detalhe, não poderia repetir palavras.

Após ter se familiarizado com o alfabeto, iniciou-se o processo de construção de sílabas simples;

Os alunos foram divididos em grupos, e foi dado para cada grupo uma família de sílabas para formar palavras; 
Cada grupo ficava atento à palavra pronunciada pela professora. Exemplo: Pato, o grupo da família do $\mathbf{P}$ e do $\mathbf{T}$ iriam à frente para formar a palavra. Todos ficavam atentos nas palavras para se posicionar corretamente, caso posicionasse as sílabas de forma errada, o aluno era orientado para fazer a correção. Fica claro que dentro de uma simples abordagem pedagógica se trabalha vários conteúdos. Ou seja, com essa brincadeira, foi trabalhado o reconhecimento das letras, das sílabas e a leitura de palavras.

\section{MATEMÁTICA}

Na disciplina de matemática o instrumento utilizado foi o ábaco, para aprender o valor posicional de cada número. Sendo que o $1^{\circ}$, da direita para a esquerda, representa a unidade, e os posteriores representam a dezena, centena, unidade de milhar e assim por diante. Foi explicado para o aluno o quanto representava cada número de acordo com o valor posicional.

No ábaco cada fileira só poderá obter 9 bolinhas. Porque se tiver dez (10) bolinhas por exemplo na unidade, ela deixa de ser unidade e passa a ser dezena, e se tiver dez (10) bolinhas na dezena, ela deixa de ser dezena e passa a ser centena e assim por diante.

$\mathrm{Na}$ etapa seguinte foi ensinado que na casa da unidade cada bolinha vale um (1).

Na casa da dezena cada bolinha vale dez (10).

Na casa da centena cada bolinha vale cem (100) e assim sucessivamente.

\section{Jeito de brincar}

É chamado um aluno de cada vez para participar da brincadeira dos numerais, e o restante fica esperando sua vez e não pode falar a resposta para o colega. A professora (mediadora) dita um valor numérico e o aluno é orientado a colocar as bolinhas nas respectivas posições e por sua vez, ler e escrever o numeral no quadro. A mediadora se reporta à turma perguntando se o valor está certo ou errado e, 
considerando um erro, como poderia concertar. Assim eles poderão compreender e entender o mundo dos numerais.

Portanto, o ábaco é um instrumento lúdico facilitador que auxilia o professor no ato de ensinar e um brinquedo para os alunos que facilita a aprendizagem. A união desses fatores possibilita uma interação alegre e prazerosa que facilita a aprendizagem, contribuindo para melhoria das habilidades de cálculo.

\section{CIÊNCIAS}

Para ensinar os conteúdos de ciências foram trabalhados da seguinte forma: A professora montou três equipes com 07 alunos e uma equipe com (06) seis alunos. Com orientações da professora os alunos confeccionaram um brinquedo denominado VaiVem. Os enfeites eram diversos! Usaram muita criatividade.

\section{Material Utilizado:}

2 garrafas peti de 2 litros;

Cordão de nylon;

Tinta colorida;

Fita adesiva colorido;

Fita crepe transparente.

Depois de pronto, os alunos começaram a brincar e durante a brincadeira, a professora começou a fazer perguntas sobre preservação do meio ambiente e saúde do corpo humano (coordenação motora).

1. Qual material foi utilizado?

2. Como a utilização desse material contribui para a preservação do meio ambiente?

3. Quais os membros do corpo que vocês estão movimentando? 
4. Para o Vai-Vem funcionar é preciso fazer quais movimentos?

\section{ANÁLISE DOS RESULTADOS}

- Foram realizadas 60 atividades na disciplina de português, 40 atividades na disciplina de matemática, e 40 atividades na disciplina de ciências.

- Na disciplina de matemática das 40 atividades todos os alunos concluíram as tarefas.

- Na disciplina de Português das 60 atividades, 35 foram concluídas e 25 não conseguiram concluir.

- $\mathrm{Na}$ disciplina de ciências das 40 atividades, 38 foram concluídas e 2 não conseguiram concluir. Conforme Gráfico 1 abaixo:

Gráfico 1: Atividades por disciplina

\section{TOTAL DE ATIVIDADES POR DISCIPLINAS}

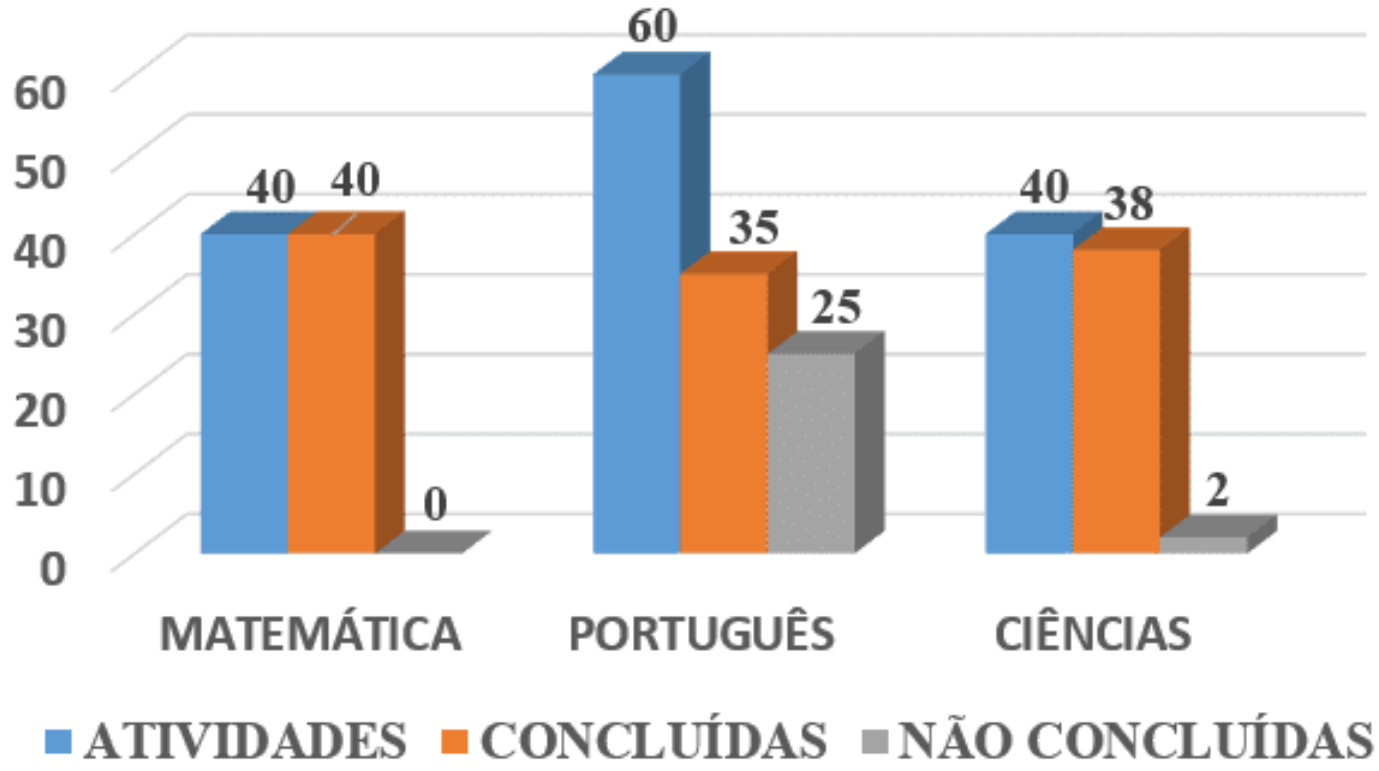

Fonte: Acervo Pessoal, 2018.[ 
Gráfico 2: Atividades de Português

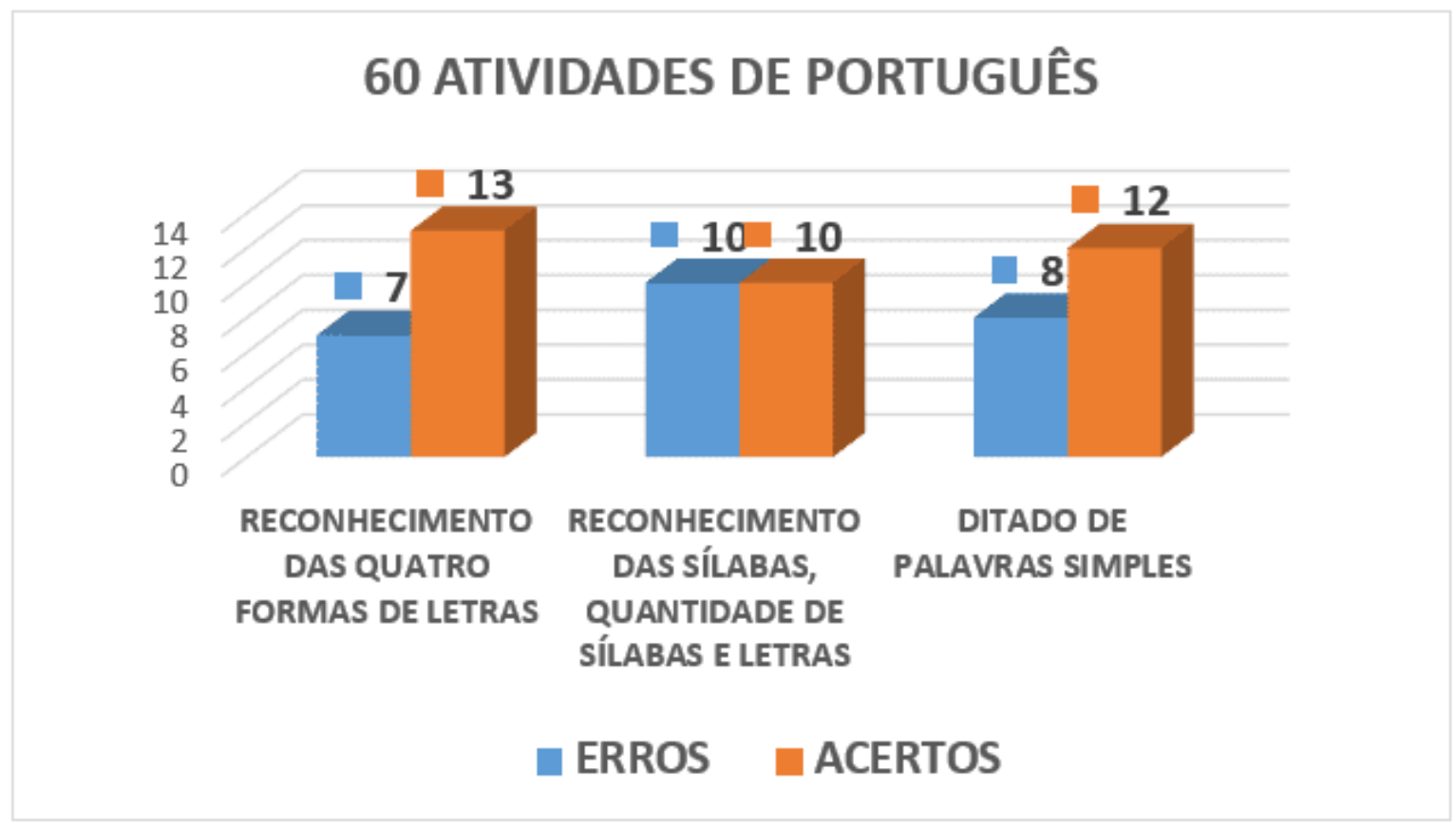

Fonte: Acervo Pessoal, 2018.

Gráfico 3. Atividades de Matemática

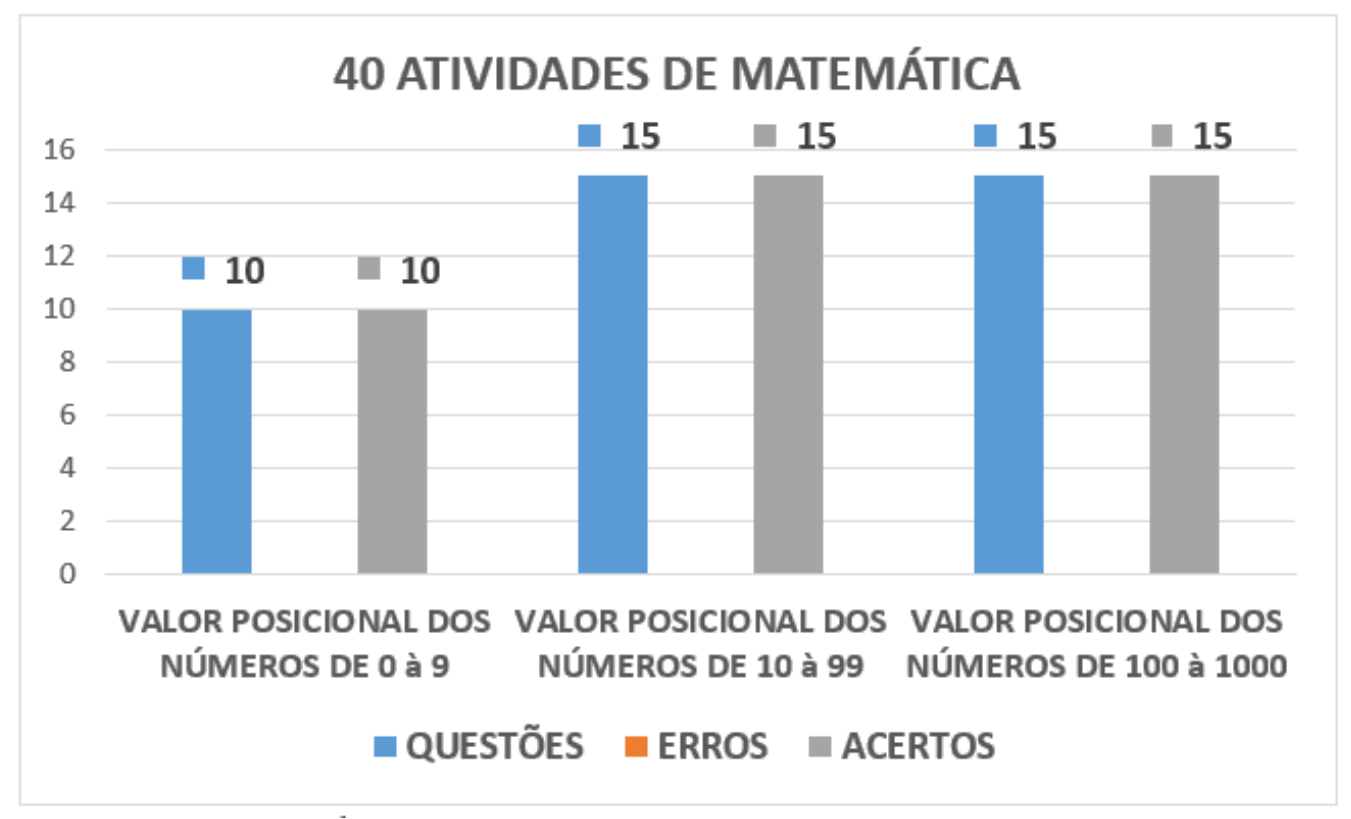

Fonte: Acervo Pessoal, 2018.

RC: 51836

Disponível em: https://www.nucleodoconhecimento.com.br/educacao/estudo-de-caso 
Gráfico 4: Atividades de Ciências

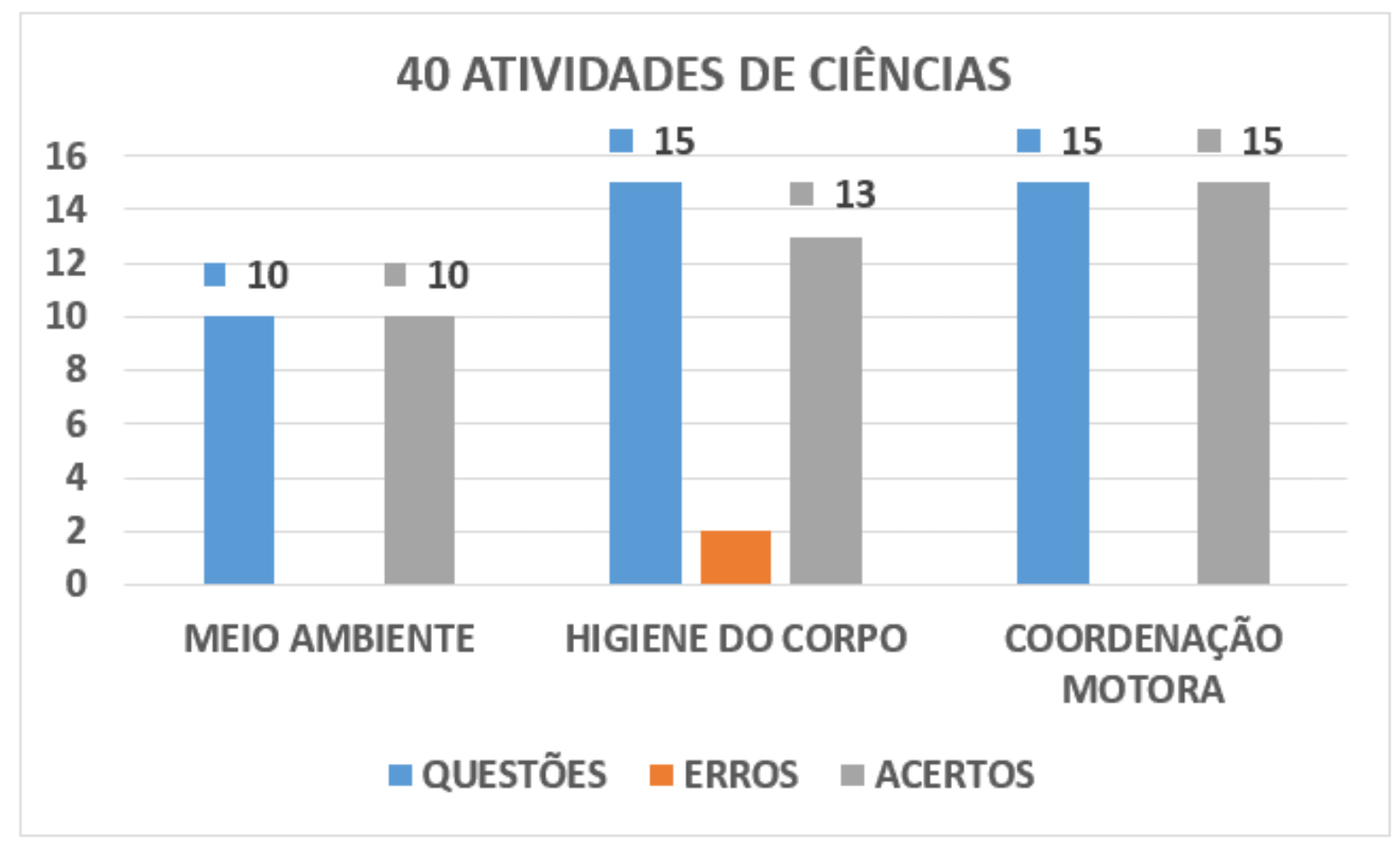

Fonte: Acervo Pessoal, 2018.

Verificou-se que na disciplina de português conforme (Gráfico 2) o conteúdo aplicado de reconhecimento das (4) quatro formas de letras, os alunos obtiveram (13) treze acertos e (7) sete erros quando responderam suas tarefas. No conteúdo de reconhecimento de sílabas simples, quantidades de sílabas e quantidade de letras os alunos realizaram 20 atividades com (10) dez acertos e (10) erros. Nas atividades de palavras simples houve (12) doze acertos e (08) erros.

Na disciplina de matemática apresentado no (Gráfico 3) das (40) quarenta atividades acertaram todas.

$\mathrm{Na}$ disciplina de ciências representado no (Gráfico 4) os alunos realizaram (40) quarenta tarefas, no conteúdo de meio ambiente houve (10) dez acertos. No conteúdo higiene do corpo foram (13) treze acertos e (02) erros. No conteúdo de coordenação motora houve (15) quinze acertos. 
Gráfico 5: Aproveitamento dos Alunos

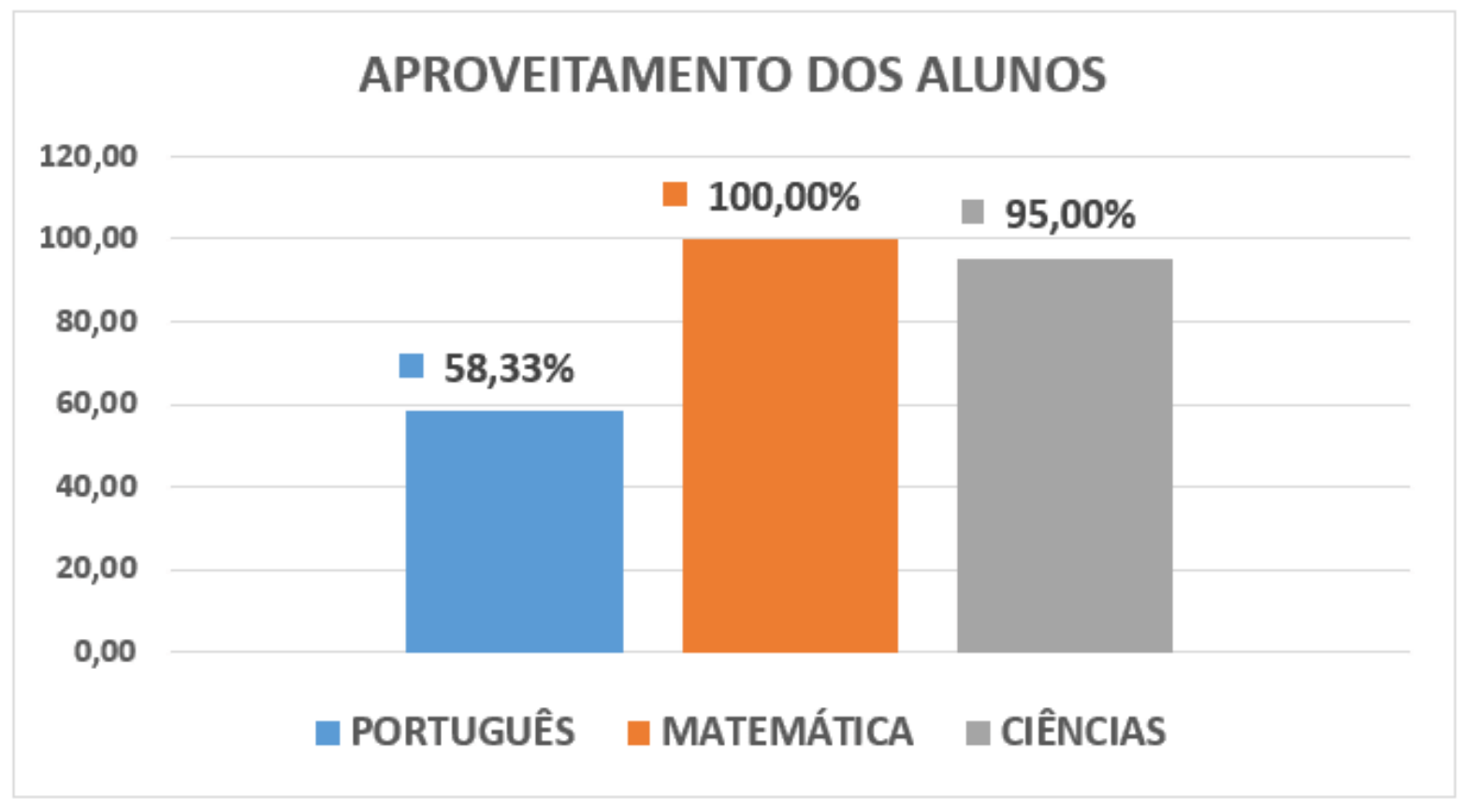

Fonte: Acervo Pessoal, 2018.

Conforme o (Gráfico 5) fica claro que houve um aproveitamento significativo e positivo com a inserção do lúdico nas disciplinas de português, matemática e ciências, ratificando uma metodologia eficiente e eficaz. Como também, o lúdico trouxe uma atmosfera positiva entre professor, alunos, pais e equipe diretiva da escola.

\section{CONCLUSÃO}

Em qualquer disciplina o envolvimento ativo do aluno é uma condição fundamental na aprendizagem, o professor precisa conhecer bem os seus alunos e criar com eles um bom ambiente de aprendizagem para que as investidas possam ser realizadas com sucesso. Os educadores devem considerar o lúdico como parceiro no processo de ensino aprendizagem, através das brincadeiras as crianças demonstram suas emoções e estabelecem relações com o meio, aprende, partilha, ganha e perde, constituindo a sua personalidade.

Além de contribuir para aquisição de novos conhecimentos, o lúdico cria uma relação mútua, desenvolve a linguagem, atenção, percepção, criatividade e habilidades para 
melhor desenvolver a aprendizagem. Com o brincar e o jogar a criança terá oportunidade de desenvolver suas habilidades, pois, quando se brinca, sua aprendizagem evolui de maneira prazerosa.

Logo, brinquedos, jogos e brincadeiras, são instrumentos indispensáveis no desenvolvimento do ensino aprendizagem.

\section{REFERÊNCIAS}

ANTUNES, C. jogos para a estimulação das múltiplas inteligências: os jogos e os parâmetros curriculares nacionais. Campinas: Papirus,2005. p.34.

LDBEN- Lei de Diretrizes e Bases da Educação Nacional. Lei no 9.394/96 de 20 de dezembro de 1996.

CHALITA, G. Educação, a solução está no afeto. São Paulo: Editora Gente, 2001, p.17.

CUNHA, Nyelse Helena Silva. Brinquedoteca: um mergulho no brincar. São Paulo: Maltese, 1994, p.67.

DALLABONA, Sandra Regina; MENDES, Sueli Maria Schimit. O lúdico na educação infantil: jogar, brincar, uma forma de educar. Revista de divulgação técnicocientífica do ICPG, v. 1, n. 4, 2004, p.06.

DANTAS, H. Brincar e Trabalhar. In: KISHIMOTO, T. M. (org). Brincar e suas teorias. São Paulo: Pioneira, 1998, p.111.

DRUMMOND, Carlos. Brincar e aprender: a importância do lúdico para as crianças pequenas. Pátio: Grupo A Editora, Porto Alegre, 2003, p.99.

FORTUNA, T.R. O Lugar do brincar na educação infantil. Revista Pátio Educação Infantil, ano IX, n.27,abr / jun.2011 ( 2011), p.11. 
FREIRE, Paulo. Pedagogia da Autonomia. Saberes necessários à prática educativa. Coleção leitura. Editora Paz e Terra, 2001,17 ed, p.44.

FRIEDMANN, Adriana. Brincar: Crescer e aprender - o resgate do jogo infantil. São Paulo: Moderna, 1996, p.55.

FURTH, Hans G. Piaget e o conhecimento: fundamentos teóricos. Trad. Valerie Rumjanek. Rio de Janeiro: Forense-Universitária, 1974, p.18.

HUIZINGA, Johan. Homo ludens: o jogo como elemento da cultura. Trad. João Paulo Monteiro. São Paulo: Perspectiva; Edusp, 1971. p.07.

IILICH, I. Celebração da consciência. 2. ed. Petrópolis: Vozes, 1976, p.23.

KAMII,C; DECLARCK,G. Reiventando a Aritimétrica, aplicaçõse da teoria de Piaget. Porto Alegre, RS,2001, p.15.

KISHIMOTO, T.M. Jogos infantis: o jogo, a criança e a educação. Petrópolis, RJ: Vozes,1993, p.108.

KISHIMOTO, Tizuco Morchida. O Jogo e a Educação Infantil: In: KISHIMOTO, Tizuco Morchida. Jogo, Brinquedo, e a Educação. São Paulo: Cortez,1996, p.26.

NEVES, Libéria Rodrigues; SANTIAGO, Ana Lydia. O uso dos jogos teatrais na educação: possibilidades diante do fracasso escolar. 2. ed. Campinas: Papirus, 2009, p.45.

PIAGET, J. Aprendizagem e conhecimento. Rio de Janeiro: Freitas Bastos, 1976, p.160.

Psicologia e Pedagogia. 3. ed. (Trad. D. A. Lindoso e R. M. R. Silva). Rio de Janeiro: Forense-Universitária, 1976. (Orig.: 1969), p.160.

SANTOS, Santa Marli Pires dos. O lúdico na formação do Educador. $6^{\underline{a}}$ ed. Petrópolis, RJ: Vozes, 1997, p.12. 
SANTOS, Santa Marli Pires Dos. Brinquedoteca: a criança, o adulto e o lúdico. 6. ed. Petrópolis: Vozes, 2008. p. 182.

VYGOTSKY, L.S. A formação so FREIRE, J. B. Educação de corpo inteiro. São Paulo, Scipione, (1984), p.114.

VYGOTSKY, L. S. A Formação Social da Mente. 6. ed. São Paulo: Martins Fontes Editora LTDA, 1998.

WALLON,H, ( 1995). Psicologia e Educaçõa da Infância. Lisboa: Estampa (1979) do acto ao pensamento. Lisboa: Moraes ( 1979), p.81.

\section{APÊNDICES}

\section{QUESTIONÁRIO APLICADO A COORDENADORA}

Escola:

Idade:

Tempo de Trabalho:

Tempo de trabalho na atual escola:

1. As atividades lúdicas auxiliam na construção do conhecimento dos alunos?

( ) Sim ( ) Não

2. Quais são os pontos positivos da utilização de atividades lúdicas na Educação?

3. As atividades lúdicas em sala de aula facilitam a relação entre a teoria e a prática?

( ) Sim ( ) Não

4. As atividades lúdicas em sala de aula favorecem a construção de conceitos e a socialização dos alunos? 
( ) Sim

( ) Não

5. Com a inserção das brincadeiras no $3^{\circ}$ ano melhorou o comportamento dos alunos?

( ) Sim

( ) Não

6. As brincadeiras favorecem a inclusão de crianças portadoras de necessidades especiais?

( ) Sim

( ) Não

7. Os alunos aprenderam com mais facilidade no ensino:

( ) Tradicional

( ) Utilizando o lúdico

8. É importante trabalhar com o lúdico?

( ) Sim

( ) Não

( ) Talvez

9. O que o lúdico provoca nos alunos?

( ) Prazer, alegria

( ) Desprazer, tristeza

10. O lúdico ajuda a desenvolver nos alunos os aspectos cognitivos, afetivos e motor?

( ) Sim

( ) Não

( ) Talvez

11. O lúdico melhorou a interação entre os alunos?

( ) $\operatorname{Sim}$

( ) Não

12-Houve evolução na aprendizagem dos alunos?

( ) $\operatorname{Sim} \quad($ ) Não 
13- Houve melhora na participação dos alunos nas atividades educativas?
( ) Sim
( ) Não

\section{QUESTIONÁRIO APLICADO PARA OS ALUNOS}

Escola:

Idade:

Série:

1. Você gosta de aprender brincando?

( ) Sim ( ) Não

2. Com as imagens das figuras e as quatro formas das letras exposta na parede facilitou a identificação das letras?
( ) Sim
( ) Não
( ) Talvez

3. Com os jogos das palavras você aprendeu melhor as sílabas, números de sílabas e quantidade de sílabas e letras?
( ) Sim
( ) Não
( ) Talvez

4. Com o ábaco você entendeu melhor os números e o seu valor de acordo com a posição que ocupa?

( ) Sim

( ) Não

) Talvez

5. Você gosta de fazer atividades somente copiando pelo quadro?

( ) Sim

( ) Não

6. Quando a professora ensina com brincadeiras você tem vontade de ir embora?

( ) Sim ( ) Não 
7. Quando a professora ensina com brincadeiras você tem vontade de voltar no dia seguinte?

( ) Sim

$$
\text { ( ) Não }
$$

8. Quando a professora conta uma história imitando o personagem você fica prestando atenção na história e nos movimentos da professora?

( ) Sim

( ) Não

09- Com o brinquedo vaivém feito por vocês, e com a orientação da professora vocês aprenderam melhor quais conteúdos?

( ) Coordenação ( ) Articulação （）Reciclagem （）nada

10- Os materiais utilizados para fazer o brinquedo vaivém foram:
( ) Comprado
( ) Reciclado

11- Gostaram do brinquedo?
( ) Sim
( ) Não

\section{QUESTIONÁRIO APLICADO PARA OS PAIS OU RESPONSÁVEIS}

Pai/Responsável:

1. Seu filho(a) mostrou mais interesse pelos estudos?

( ) Sim

( ) Não

2. Com relação ao ano anterior seu filho (a) se desenvolveu mais?

( ) Sim

( ) Não

3. O que você percebeu na expressão do rosto do seu filho (a) quando ele retorna para casa? 
( ) Alegria, satisfação

( ) Tristeza, desânimo

4. Seu filho (a) conta que quando brinca ele aprende?

( ) Sim

( ) Não

5. Você percebeu que seu filho (a) está mais participativo?

( ) $\operatorname{Sim}$

( ) Não

6. Você percebeu que seu filho (a) está mais comunicativo?

( ) Sim

( ) Não

7. O que você acha da metodologia de ensinar brincando?

( ) Ruim ( ) Regular ( ) Bom ( ) ótimo

8. Você acha que os jogos, os brinquedos e as brincadeiras inseridos nos conteúdos, melhoram o desenvolvimento e a aprendizagem?

( ) Sim ( ) Não

26. A metodologia utilizada pela professora em inserir o lúdico no ensino aprendizagem desenvolve o aluno? ( ) Sim

( ) Não 


\section{ANEXOS}

Imagem 01 - Fachada do Colégio Estadual Pedro Alves de Souza - Lagoa da Volta/Porto da Folha/Sergipe

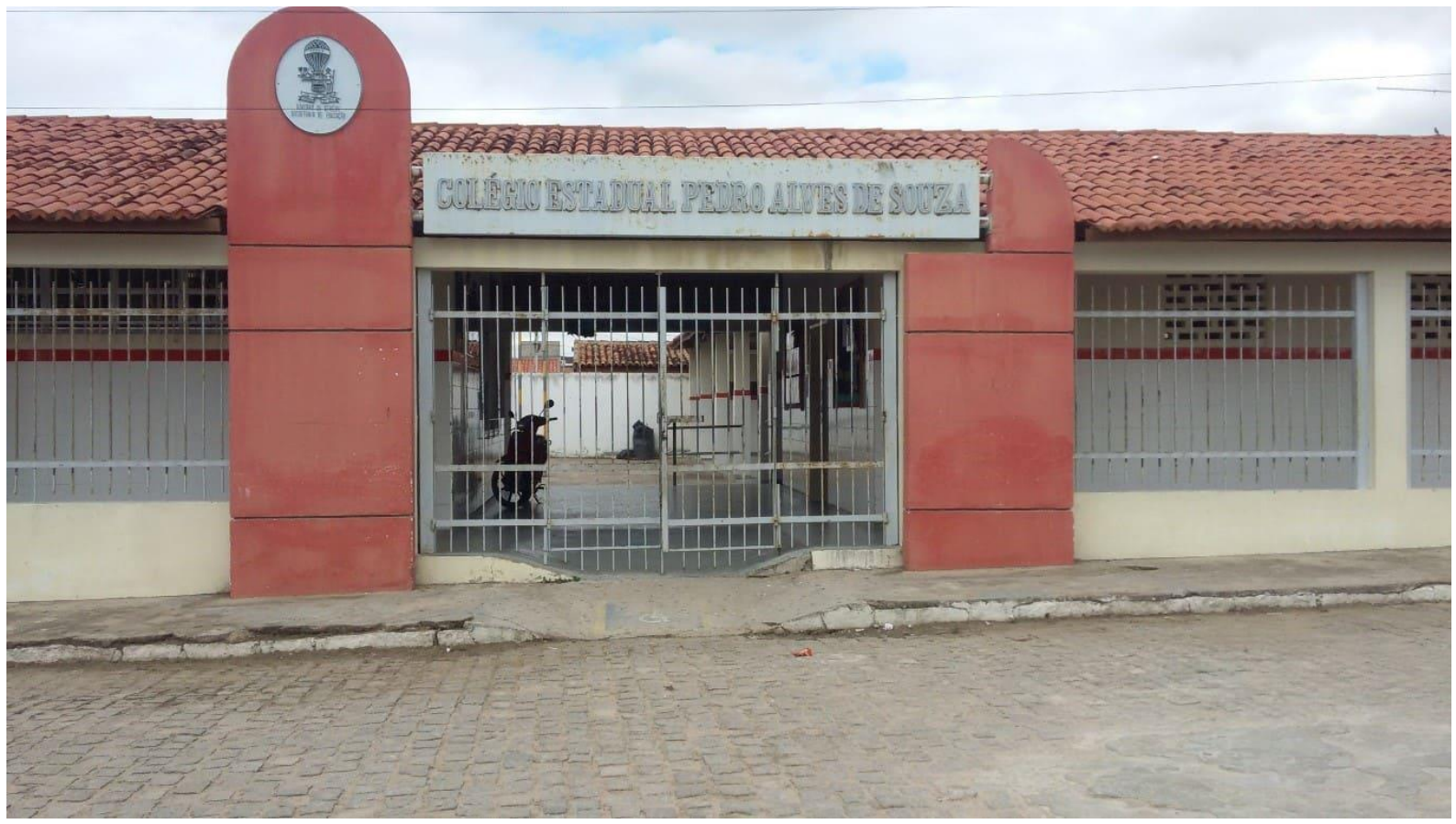

Imagem 02 - Ciências: Atividade Lúdica: Brinquedo Vai vem

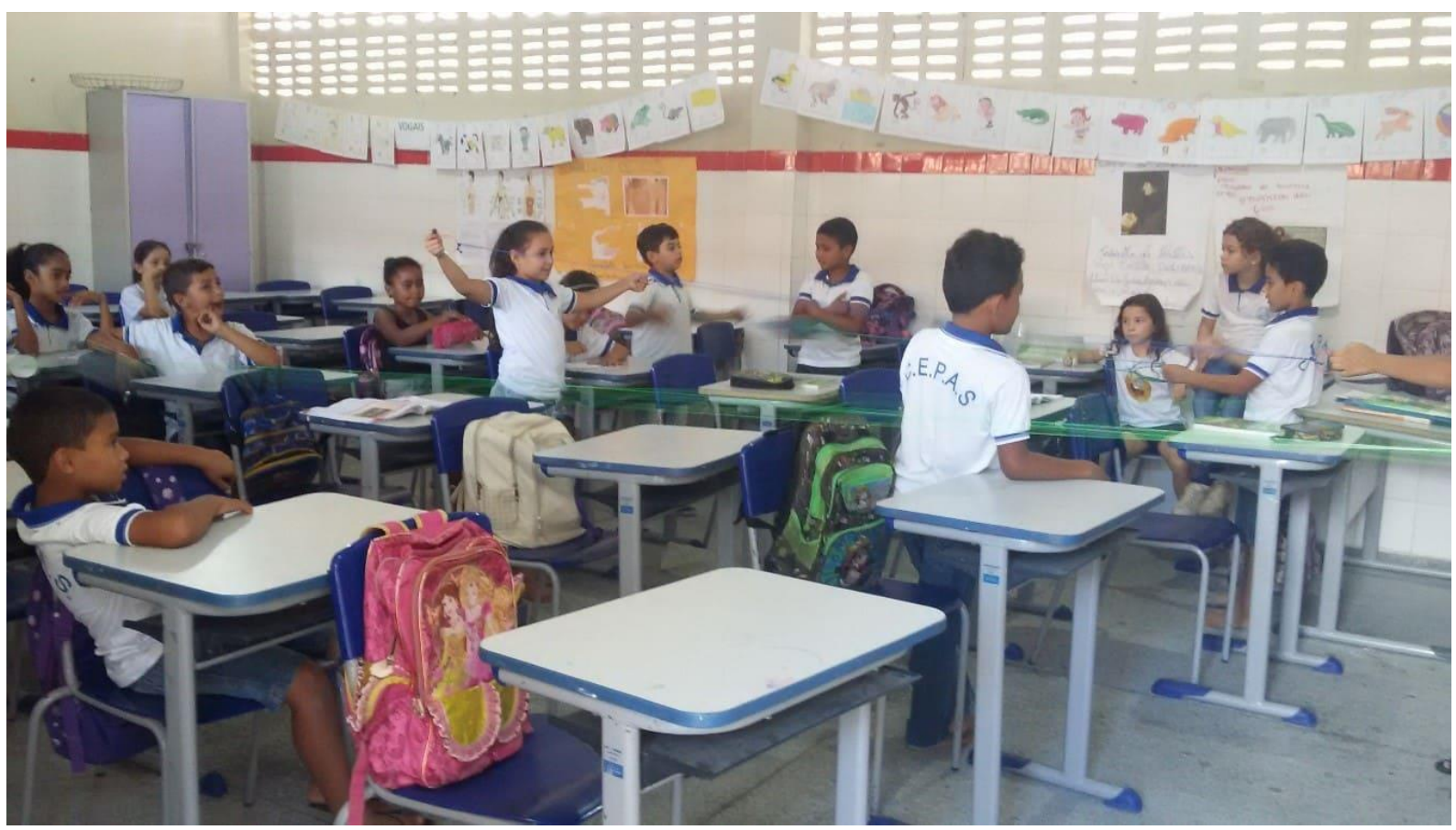

$\mathrm{RC}: 51836$

Disponível em: https://www.nucleodoconhecimento.com.br/educacao/estudo-de-caso 
Imagem 03-Ciências: Atividade Lúdica: Brinquedo Vai vem

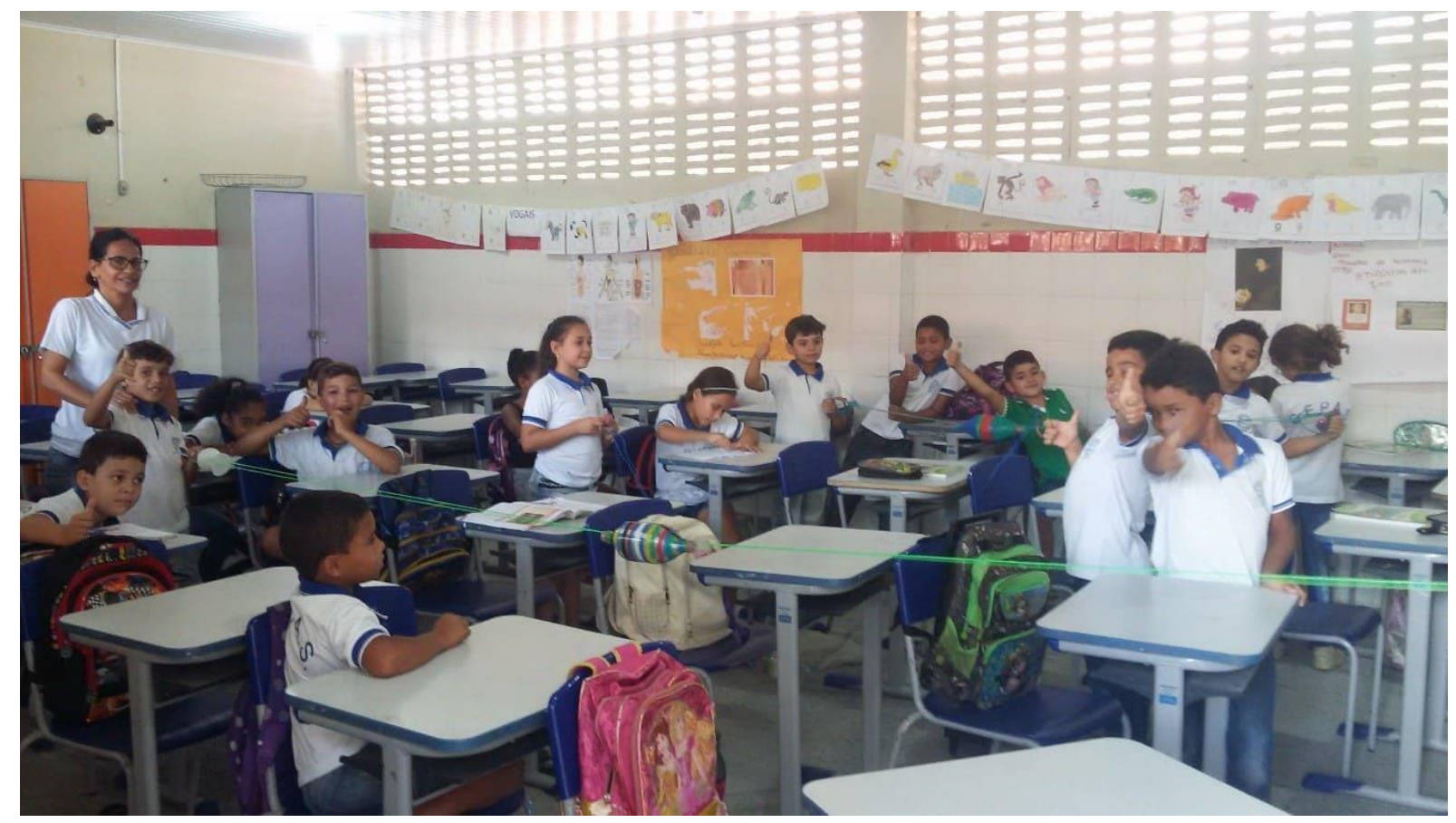

Imagem 04 - Português: Letras e imagens expostas na parede.

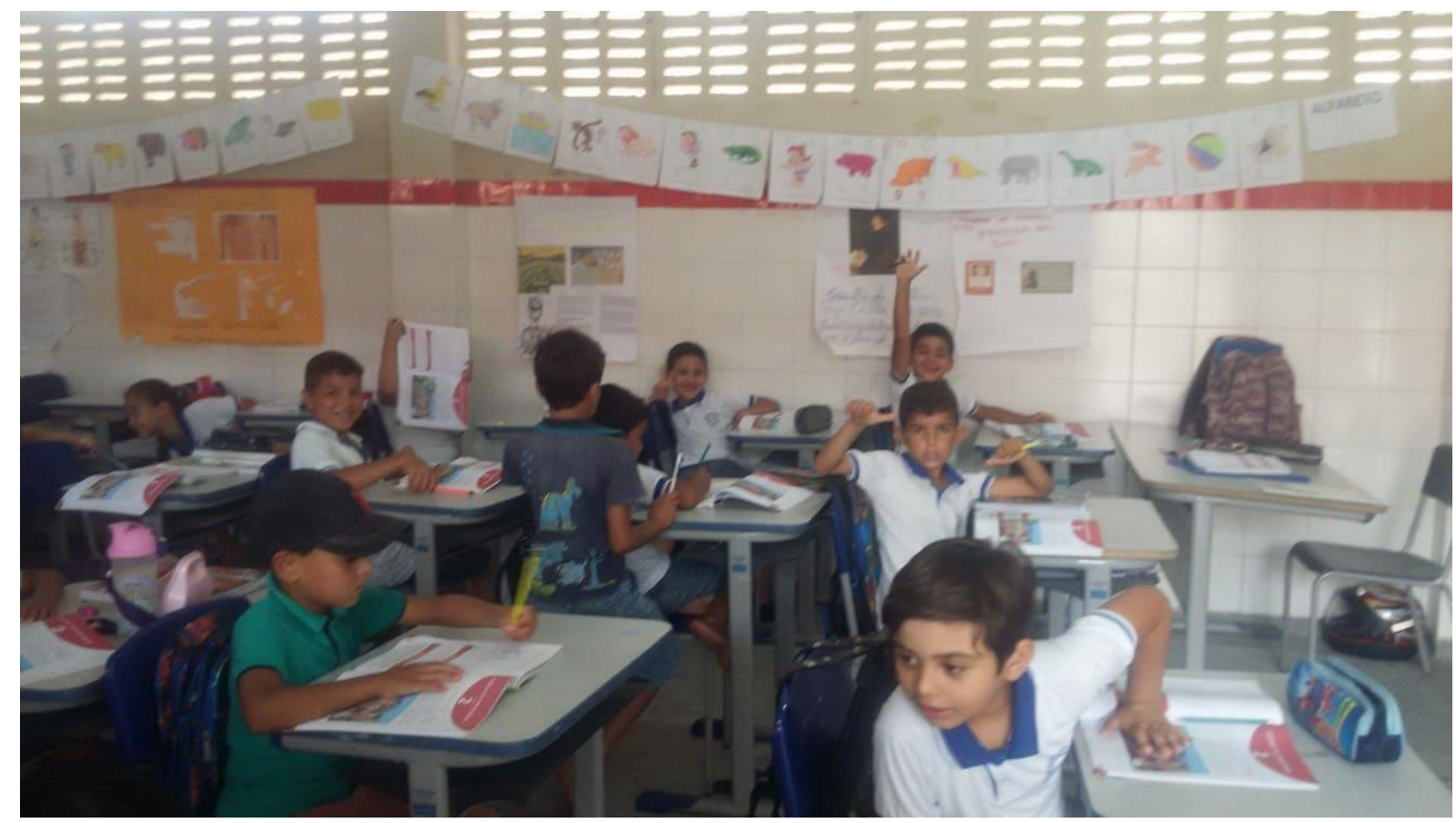

$\mathrm{RC}: 51836$

Disponível em: https://www.nucleodoconhecimento.com.br/educacao/estudo-de-caso 
Imagem 05 - Português: Letras e imagens expostas na parede.

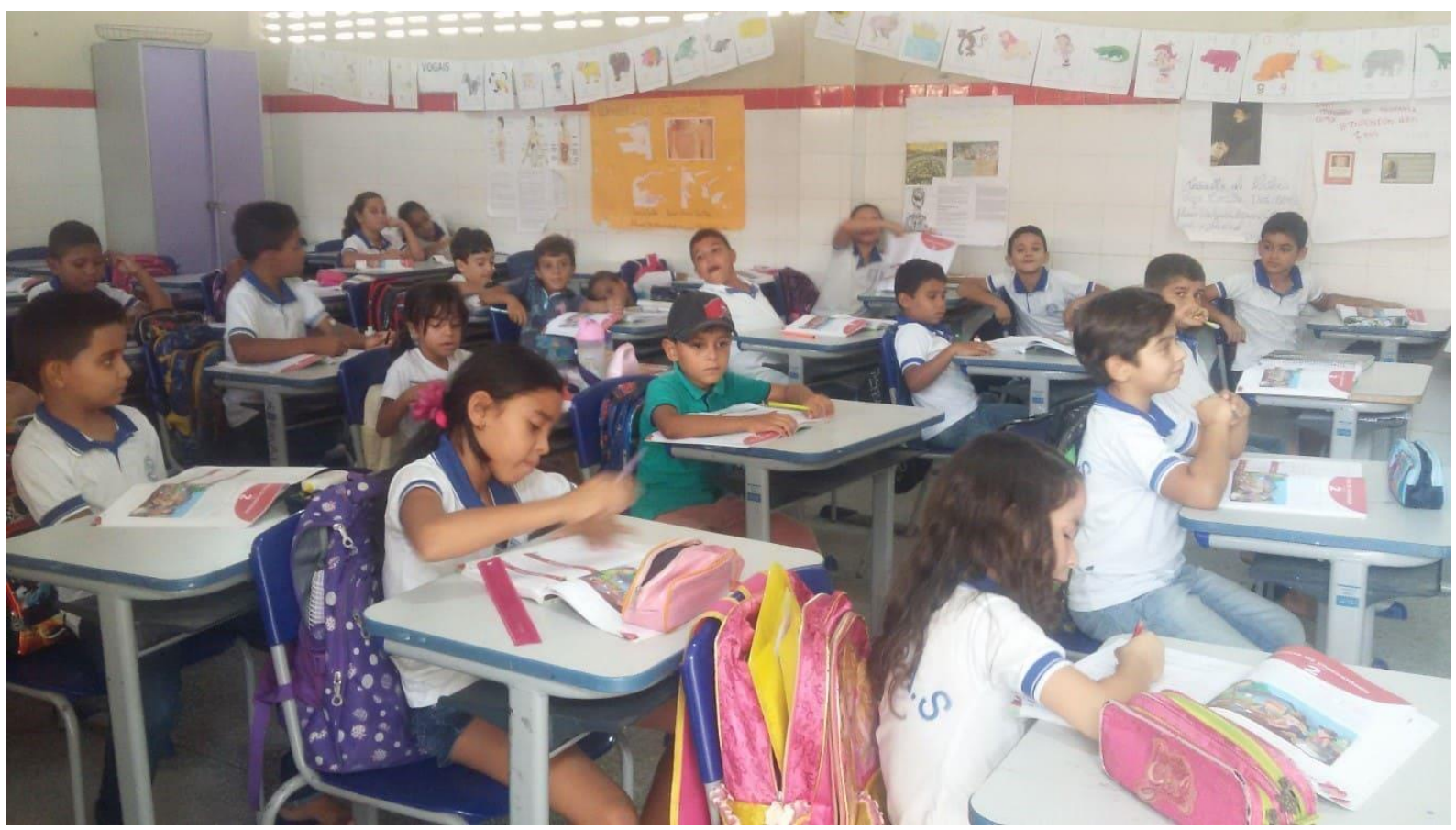

Imagens 06 - Matemática: Trabalhando com Ábaco.

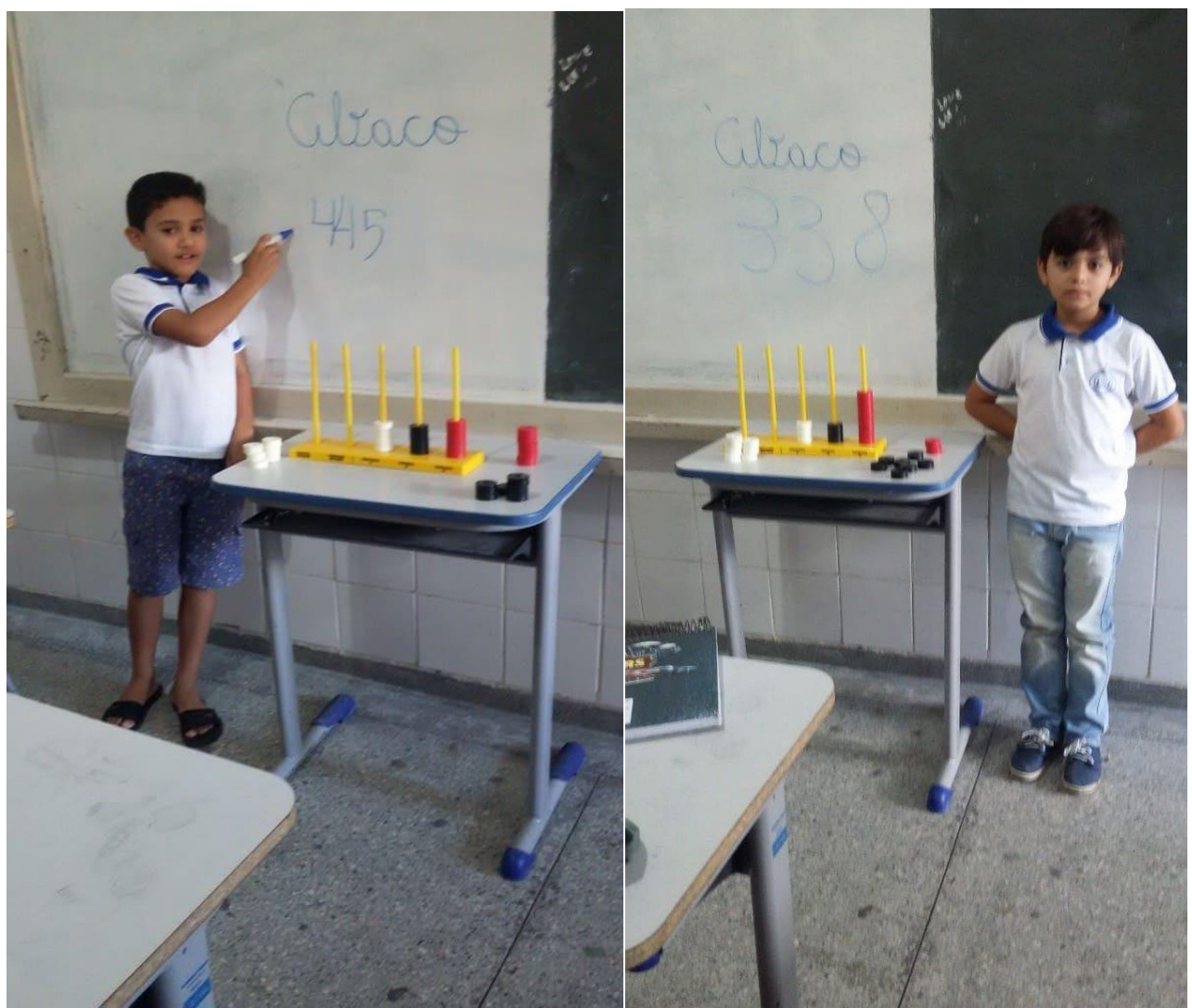

$\mathrm{RC}: 51836$

Disponível em: https://www.nucleodoconhecimento.com.br/educacao/estudo-de-caso 
Enviado: Maio, 2020.

Aprovado: Junho, 2020. 